\title{
Phylogenetic relationships and pathogenicity variation of two Newcastle disease viruses isolated from domestic ducks in Southern China
}

Yinfeng Kang ${ }^{1,2,3,4}$, Yanling Li $i^{1,2,3,4}$, Runyu Yuan ${ }^{1,2,3,4}$, Xianwei Li $i^{1,2,3,4}$, Minhua Sun 1,2,3,4, Zhaoxiong Wang ${ }^{1,2,3,4}$, Minsha Feng ${ }^{1,2,3,4}$, Peirong Jiao ${ }^{1,2,3,4^{*}}$ and Tao Ren ${ }^{1,2,3,4^{*}}$

\begin{abstract}
Background: Newcastle disease (ND) is an OIE listed disease caused by virulent avian paramyxovirus type 1 (APMV-1) strains, which is enzootic and causes large economic losses in the poultry sector. Genotype VII and genotype IX NDV viruses were the predominant circulating genotype in China, which may possibly be responsible for disease outbreaks in chicken flocks in recent years. While ducks and geese usually have exhibited inapparent infections.

Methods: In the present study, we investigate the complete genome sequence, the clinicopathological characterization and transmission of two virulent Newcastle disease viruses, $\mathrm{SS}-10$ and $\mathrm{NH}-10$, isolated from domestic ducks in Southern China in 2010.

Results: F, and the complete gene sequences based on phylogenetic analysis demonstrated that SS-10 (genotype VII) and NH-10 (genotype IX) belongs to class II. The deduced amino acid sequence was ${ }^{(112)} \mathrm{R}-\mathrm{R}-\mathrm{Q}-\mathrm{K} / \mathrm{R}-\mathrm{R}-\mathrm{F}^{(117)}$ at the fusion protein cleavage site. Animal experiment results showed that the SS-10 virus isolated from ducks was highly pathogenic for chickens and geese, but low pathogenic for ducks. It could be detected from spleen, lung, kidney, trachea, small intestine, bursa of fabricius, thymus, pancreas and cecal tonsils, oropharyngeal and cloacal swabs, and could transmit to the naive contact birds. Moreover, it could transmit to chickens, ducks and geese by naive contact. However, the NH-10 virus isolated from ducks could infect some chickens, ducks and geese, but only caused chickens to die. Additionally, it could transmit to the naive contact chickens, ducks, and geese.

Conclusion: The two NDV isolates exhibited different biological properties with respect to pathogenicity and transmission in chickens, ducks and geese. Therefore, no species-preference exists for chicken, duck or goose viruses and more attention should be paid to the trans-species transmission of VII NDVs between ducks, geese and chickens for the control and eradication of ND.
\end{abstract}

Keywords: Newcastle disease virus, Phylogenetic analysis, Pathogenicity, Transmission

\section{Background}

Newcastle disease (ND) is caused by specified viruses of the avian paramyxovirus type I (APMV-1) serotype of the genus Avulavirus belonging to the family Paramyxoviridae [1]. There are 11 serotypes of avian paramyxoviruses designated APMV-I to APMV-11 and Newcastle

\footnotetext{
*Correspondence: prjiao@yahoo.com; renta06868@126.com

'National and Regional Joint Engineering Laboratory for Medicament of Zoonosis Prevention and Control, Guangzhou, China

${ }^{2}$ Key Laboratory of Animal Vaccine Development, Ministry of Agriculture, Guangzhou, China

Full list of author information is available at the end of the article
}

disease virus (NDV) has been designated APMV-1. Since its recognition in 1926, ND is regarded as being endemic in many countries. NDV is characterized by pathogenesis in chickens and has been categorized into three main pathotypes, based on the clinical signs seen in infected chickens [2]. Lentogenic isolates are of low virulence and cause mild respiratory or enteric infections. Viruses of intermediate virulence can cause primarily respiratory disease, while viruses of velogenic virulent can cause high mortality. Velogenic forms of NDV are further classified as neurotropic or viscerotropic based on 
clinical manifestation. OIE defines ND as an infection caused by an APMV-1 virus with an intracerebral pathogenicity index (ICPI) of 0.7 or greater in day-old chickens or by multiple basic amino acids at the $\mathrm{F}$ protein cleavage site [3]. Previous studies had compared the precursor peptide $\mathrm{F}$ amino acid sequences of NDV strains that varied in their virulence, and showed that virulent viruses had the amino acid sequence ${ }^{112} \mathrm{R} / \mathrm{K}-\mathrm{R}-\mathrm{Q}-\mathrm{K} / \mathrm{R}-\mathrm{R}^{116}$ at the $\mathrm{C}$ terminus of the $\mathrm{F} 2$ protein and phenylalanine at residue 117 at the $\mathrm{N}$ terminus of the $\mathrm{F} 1$ protein. However, viruses with low levels of virulence had the sequence ${ }^{112} \mathrm{G} / \mathrm{E}-\mathrm{K} / \mathrm{R}-\mathrm{Q}-$ $\mathrm{G} / \mathrm{E}-\mathrm{R}^{116}$ at the $\mathrm{C}$ terminus of the $\mathrm{F} 2$ protein and leucine at residue 117 at the $\mathrm{N}$ terminus of the F1protein [4-9].

In China, Newcastle disease was first described in 1946 [10] and, since then, outbreaks have been regularly reported in the rural poultry of Southern China [11-13]. Genotype VII NDV viruses were the predominant circulating genotype in China, which may possibly be responsible for disease outbreaks in chicken flocks in recent years. While the genotype IX viruses, to which the China challenge strain F48E8 used for vaccine evaluation belongs, were found only in China and still induced sporadic infections in certain areas [10]. Additionally, ducks and geese usually have inapparent infections, but some isolates (genotypes VII and VI) have caused outbreaks among geese in China since the 1990s [12,14]. Clinical cases have been also been described occasionally in ducks.

In the present study, two NDVs isolated from outbreaks in domestic ducks in China during 2010 were genotypically and pathotypically characterized. The pathogenicity and transmission of SS-10 strain and NH-10 strain were evaluated in chickens, ducks and geese, which provided experimental reference data to the integrate control and prevention of ND in waterfowl.

\section{Results}

Biological characterization assessment of the two isolates The initial biological characterizations of the two NDV isolates, including the MDT and ICPI, are presented in Table 1. This table also shows the virulence index of these viruses, the MDT, ICPI of isolate SS-10 were $51.6 \mathrm{~h}$ and 1.89 , while those of $\mathrm{NH}-10$ were $58.8 \mathrm{~h}$ and 1.7 , which were typical of velogenic NDV strains.

\section{Sequence analysis}

The results of virulence tests, as determined by the MDT and ICPI tests, were for the most part, in accordance with those determined by the F0 protein proteolytic cleavage site motifs (residues 112 to 117). Strain SS-10 shared the cleavage site motif ${ }^{112} \mathrm{RRQKRF}^{117}$, while strain $\mathrm{NH}-10$ contained the ${ }^{112}{ }^{12 R Q R R F}{ }^{117}$, which are a molecular characteristic of virulent NDV strains. The nucleotide sequence data were deposited into the GenBank database and the accession numbers were KF219497 (SS-10) and KF219498 (NH-10). The genome of the two isolates (SS-10, NH-10) are 15,192 nt in length, containing a six nucleotides insertion in the $5^{\prime}$-noncoding region (NCR) of the nucleoprotein gene between positions 1738 and 1743 and $\mathrm{G}+\mathrm{C}$ content of $46.48 \%, 46.72 \%$, respectively. Additionally, nucleotide sequences of the 3 ' leader and 5' trailer regions of the two NDV isolates which have identical to length, $55 \mathrm{nt}$ or $114 \mathrm{nt}$, respectively. The two NDV isolates contain mRNA edit site (UUUUUCC $\downarrow C$ ) in positions 484 nt of the P gene.

\section{Phylogenetic analysis}

According to the phylogenetic tree of $\mathrm{F}$ gene (nt 1 to 1662) and the complete genome (1 to $15192 \mathrm{nt}$ ) [15] which were based on 62 genome-scale that is shown in (Figure 1). The phylogeny showed that SS-10 isolated from Guangdong-Sanshui belonged to genotype VII, and NH-10 isolated from Guangdong-Nanhai belonged to genotype IX. The whole genome sequences of the two isolates and 62 reference strains have high homologies of $83.6 \%$ to $99.8 \%$. Strain SS-10 showed greatest nucleotide identities (99.2\%) with the velogenic strain GM (Accession number DQ486859). In addition, the isolate was highly similar to ZJ/1, CK/CH/GD/1/05, CZ/10/08/CH, and dove/Guangxi/15/2005, which displayed a nucleotide sequence homology of 96.6 to $98.9 \%$. Strain NH-10 showed higher sequence homology among strains having the same genotype. For example, Strain NH-10 (genotype IX) had nucleotide homologies of $99.8 \%, 99.7 \%$, 99.7\%, 99.6\% with JS/1/02/Du, JS/1/97, and ZJ/1/86/CH, respectively. The homologies of nucleotide sequences were relatively low between different genotypes. The F-gene full-length amino acid sequences of the two field isolates were compared with those of reference viruses representing different genotypes. The results showed

Table 1 Sequential information and pathogenicity of two viruses in this study

\begin{tabular}{|c|c|c|c|c|c|c|c|}
\hline Isolate name & Host & Separatum & Isolate year & $\mathrm{EID}_{50} / 0.2 \mathrm{ml}$ & $\mathrm{ICPI}^{\mathrm{a}}$ & $\operatorname{MDT}(h)^{b}$ & Fusion protein cleavage site ${ }^{c}$ \\
\hline SS-10 & Duck & Sanshui & 2010 & $10^{-9.83}$ & 1.89 & 51.6 & ${ }^{112} \mathrm{RRQKRF}^{117}$ \\
\hline $\mathrm{NH}-10$ & Duck & Nanhai & 2010 & $10^{-9.62}$ & 1.7 & 58.8 & ${ }^{112} \mathrm{RRQRRF}^{117}$ \\
\hline
\end{tabular}

${ }^{\mathrm{a}} \mathrm{A}$ strain with an ICPI below 0.7 was considered to be lentogenic, while those with an ICPI equal to or greater than 1.60 were considered to be velogenic, and those with ICPI values between 0.7 and 1.60 were considered to be mesogenic. The ICPI of avirulent viruses were near 0.00 [2].

${ }^{b}$ For 9-day-old embryonated chicken eggs, the mean death time (MDT) value (h) of more than 90 was defined as lentogenic; $60-90$ as mesogenic, and under 60 as velogenic.

${ }^{\mathrm{C} C l e a v a g e}$ site sequences (residues 112 to 117 ) of the $\mathrm{F}$ protein. 

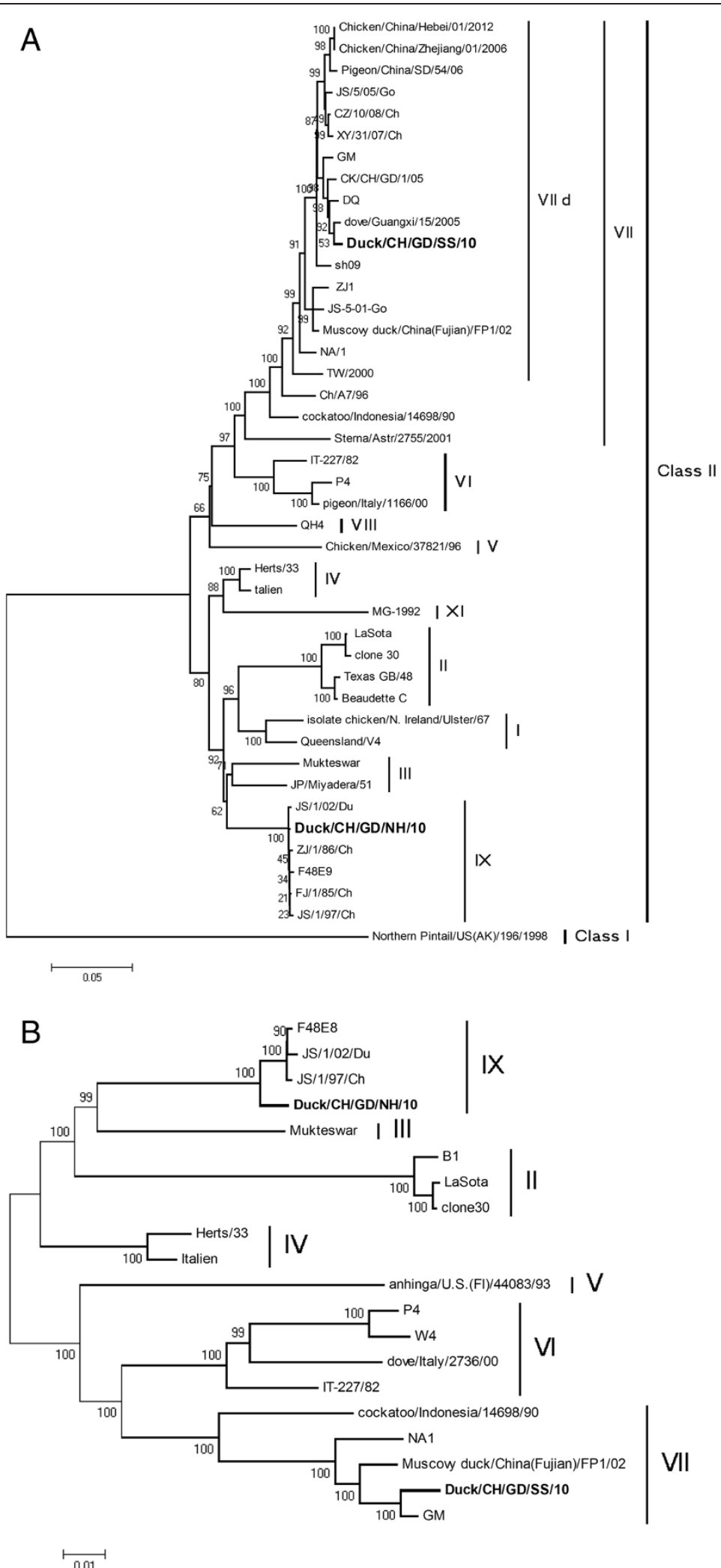

Figure 1 Phylogenetic relationships of the nucleotide sequences of 62 NDV strains based on the entire ORF (1 to 1,662 nt) of the F gene (A) and the complete gene (B) (nt 1 to 15192). Sequences previously published in GenBank are listed in Materials and methods and Additional file 1: Table S1. The phylogram was generated by the neighbor-joining method using MEGA 4 software [16]. 
that SS-10 and NH-10 had sequence homologies of $83.6 \%$ and $89.3 \%$ at the nucleotide level with vaccine strain Lasota, respectively. No recombination events were observed in the two isolates (SS-10, NH-10) genome (date not shown).

\section{Animal experiment}

Pathogenicity and transmission in chickens In order to investigate the pathogenicity of these three viruses in chickens, we inoculated intranasally with $10^{6} \mathrm{EID}_{50}$ of SS-10 or NH-10 viruses in a volume of $200 \mu \mathrm{l}$ in SPF chickens, respectively. Then all the chickens were observed for 14 days after infection.

All the chickens of the SS-10 group died within 6 DPI. All the chickens inoculated with NH-10 died within 5 DPI (Table 2). The SS-10 and NH-10 viruses replicated systemically in chickens, which could be detected from all the tested organs on 3 DPI, including the heart, liver, spleen, lung, kidney, brain, trachea, small intestine, bursa of fabricius, thymus, pancreas and cecal tonsils. The SS-10 or NH-10 viruses replicated highly in lung; the mean titers were $8.33 \log _{10} \mathrm{EID}_{50}$ and $7.5 \log _{10} \mathrm{EID}_{50}$, respectively (Table 3 ). In addition, the SS-10 or NH-10 viruses replicated in lymphoid tissues(spleen, bursa of fabricius, thymus and cecal tonsils), whose virus titers were from $6.67 \log _{10} \mathrm{EID}_{50}$ to $7.5 \log _{10} \mathrm{EID}_{50}$.

SS-10 and NH-10 viruses shedding from the inoculated chickens were detected in oropharyngeal and cloacal swabs at 3, 5, 7, 9 and 11 DPI. The SS-10 and NH-10 viruses could be tested from both oropharyngeal and cloacal swabs of inoculated chickens until they died within 6 DPI (Table 4). The SS-10 virus was shed from the oropharynx in inoculated chickens within 5 DPI, whose virus titers were from $2.67 \log _{10} \mathrm{EID}_{50}$ to $4.30 \log _{10} \mathrm{EID}_{50}$. It also could be shed from the cloaca within 5 DPI; the virus titers were from $1.75 \log _{10} \mathrm{EID}_{50}$ to $4.5 \log _{10} \mathrm{EID}_{50}$ (Table 4). $\mathrm{NH}-10$ virus shedding could be tested from both oropharyngeal and cloacal swabs at 3 and 5 DPI. The virus titers were from $3.58 \log _{10} \mathrm{EID}_{50}$ to $4.5 \log _{10} \mathrm{EID}_{50}$ in oropharyngeal swabs and $4.04 \log _{10} \mathrm{EID}_{50}$ to $5.25 \log _{10} \mathrm{EID}_{50}$ in cloacal swabs (Table 4).

To understand the horizontal transmission of these two viruses, three SPF chickens were inoculated intranasally with $0.2 \mathrm{ml}$ phosphate buffered saline (PBS) as a naive contact group, which was housed with those inoculated with the SS-10 or NH-10 viruses.

During the observed time, two of the three naive contact chickens housed with SS-10 died on 6 DPI; the rest of the naive contact chickens seroconverted on 14 DPI (Table 4). The virus could be detected from oropharyngeal and cloacal swabs within 7 DPI. The virus titers were from $1.75 \log _{10} \mathrm{EID}_{50}$ to $3.42 \log _{10} \mathrm{EID}_{50}$ in oropharyngeal swabs and $1.75 \log _{10} \mathrm{EID}_{5}$ to $3.17 \log _{10} \mathrm{EID}_{50}$ in cloacal swabs (Table 4). All the chickens in the naive contact group, housed with inoculated SS-10 chickens, died within 5 DPI. The virus could be detected from oropharyngeal swabs and cloacal swabs at 3 and 5 DPI. The mean titers were from $2.42 \log _{10} \mathrm{EID}_{50}$ to 4.25 $\log _{10} \mathrm{EID}_{50}$ in oropharyngeal swabs and $2.58 \log _{10} \mathrm{EID}_{5}$ to $4.67 \log _{10} \mathrm{EID}_{50}$ in cloacal swabs (Table 4).

Our results indicated that SS-10 and NH-10 viruses were highly pathogenic to chickens, and could transmit between chickens by naive contact.

Pathogenicity and transmission in ducks To determine the pathogenicity in ducks, we inoculated intranasally ducks with $10^{6} \mathrm{EID}_{50}$ of SS-10 or NH-10 virus in a volume of $200 \mu \mathrm{l}$, and then observed the ducks for 2 weeks after infection.

No ducks died during the observation period. All the ducks seroconverted in the SS-10 and NH-10 groups (Table 2). The SS-10 virus caused systemic infection in ducks, including the spleen, lung, kidney, brain, trachea, small intestine, bursa of fabricius, thymus, pancreas and cecal tonsils. The virus replicated more highly in the thymus (4.08 $\left.\log _{10} \mathrm{EID}_{50}\right)$. The mean virus titers in the spleen, lung, kidney, brain, trachea, small intestine, bursa of fabricius, pancreas and cecal tonsils were 3.58, 2.58, $2.17,1.58,2.00,2.75,3.83,2.17$ and $2.67 \log _{10} \mathrm{EID}_{50}$, respectively. The NH-10 virus replicated in some tested organs, including heart, lung, spleen, kidney, trachea, small intestine, bursa of fabricius, thymus, pancreas and cecal tonsils, but not the brain (Table 5). The mean virus titer was higher in the thymus $\left(4.17 \log _{10} \mathrm{EID}_{50}\right)$.

SS-10 and NH-10 viruses shedding from the inoculated ducks were detected in oropharyngeal and cloacal

Table 2 Lethality in chicken, ducks and geese of NDV after inoculated intranasally

\begin{tabular}{|c|c|c|c|c|c|c|}
\hline \multirow[t]{2}{*}{ Strains } & \multicolumn{2}{|c|}{ Manifestations of chicken } & \multicolumn{2}{|c|}{ Manifestations of ducks } & \multicolumn{2}{|c|}{ Manifestations of geese } \\
\hline & No. D/S/total ${ }^{\mathrm{a}}$ & No. S.C./total ${ }^{\mathbf{b}}$ & No. D/S/total & No. S.C./total & No. D/S/total & No. S.C./total \\
\hline SS-10 & $3 / 3 / 3$ & $1 / 3$ & $0 / 1 / 3$ & $3 / 3$ & $1 / 1 / 3$ & $3 / 3$ \\
\hline $\mathrm{NH}-10$ & $3 / 3 / 3$ & $--^{c}$ & $0 / 0 / 3$ & $3 / 3$ & $0 / 1 / 3$ & $3 / 3$ \\
\hline
\end{tabular}

${ }^{a}$ No. D/S/total shows the number of dead (D) and sick (S) as well as the total number of animals from the observation period. The animals that showed disease signs, such as depression and ruffled feathers, but recovered at the end of the observation were counted as sick animals.

${ }^{b}$ No. S.C./total shows the number of animals that seroconverted out of the total number of ducks at the end of the observation period.

${ }^{\mathrm{C}} \mathrm{All}$ the chickens died at the end of the observation. 
Table 3 Replication in chickens of NDV after inoculated intranasally ${ }^{a}$

\begin{tabular}{crc}
\hline Virus replication on 3 DPI $\left(\log _{10} \mathrm{EID}_{\mathbf{5 0}} / \mathbf{g}\right)^{\mathbf{b}}$ in: & \multicolumn{2}{c}{ Strains } \\
\cline { 2 - 3 } & \multicolumn{1}{c}{ SS-10 } & NH-10 \\
\hline Heart & $4.56 \pm 0.88$ & $4.58 \pm 0.58$ \\
Liver & $5.5 \pm 0.25$ & $5.42 \pm 0.14$ \\
Spleen & $7.42 \pm 0.14$ & $7.08 \pm 0.29$ \\
Lung & $8.33 \pm 0.14$ & $7.5 \pm 0.25$ \\
Kidney & $6.17 \pm 0.38$ & $5.83 \pm 0.63$ \\
Brain & $5.08 \pm 0.58$ & $4.5 \pm 0.91$ \\
Trachea & $6.08 \pm 0.29$ & $5.08 \pm 0.76$ \\
Small intestine & $7.33 \pm 0.14$ & $6.83 \pm 0.63$ \\
Bursa of fabricius & $7.33 \pm 0.14$ & $7.42 \pm 0.14$ \\
Thymus & 7.5 & $7.17 \pm 0.38$ \\
Pancreas & $4.83 \pm 1.38$ & $5.75 \pm 0.5$ \\
Cecal tonsils & $7.5 \pm 0.25$ & $6.67 \pm 0.52$ \\
\hline
\end{tabular}

${ }^{a}$ Six-week-old chickens were inoculated intranasally (i.n.) with $10^{6} \mathrm{EID}_{50}$ of each virus in a $0.2 \mathrm{ml}$ volume; three chickens in each group were euthanized on 3 $\mathrm{DPI}$, and virus titer was determined in samples of heart, liver, spleen, lung, kidney, brain, trachea, Small intestine, bursa of fabricius, Thymus, Pancreas and cecal tonsils in eggs [17].

${ }^{\mathrm{b}}$ For statistical analysis, a value of 1.5 was assigned if the virus was not detected from the undiluted sample in three embryonated hen eggs. Virus titers are expressed as means \pm standard deviation in $\log _{10} \mathrm{EID}_{50} / \mathrm{g}$ of tissue.

swabs at 3, 5, 7, 9 and 11 DPI. The SS-10 virus could be detected in both oropharyngeal and cloacal swabs within 3 DPI (Table 6). The mean virus titers in the oropharyngeal and cloacal swabs were $1.96 \log _{10} \mathrm{EID}_{50}$ and 1.89 $\log _{10} \mathrm{EID}_{50}$, respectively. In the NH-10 group, the virus titers of oropharyngeal swabs could only be detected at 3 DPI $\left(2.17 \log _{10} \mathrm{EID}_{50}\right)$. The virus titers of the cloacal swabs were from $1.58 \log _{10} \mathrm{EID}_{50}$ to $2.17 \log _{10} \mathrm{EID}_{50}$ within 7 DPI.

To study the horizontal transmission of these two viruses, three ducks were inoculated intranasally with $0.2 \mathrm{ml}$ phosphate buffered saline (PBS) as a naive contact group housed with those inoculated with the viruses previously mentioned.

The naive contact ducks, housed with the ducks inoculated SS-10 or NH-10, experienced no deaths during the test time. SS-10 viruses shedding of the naive contact group could be detected in the oropharyngeal and the cloacal swabs. The virus titers were from $1.75 \log _{10} \mathrm{EID}_{50}$ to $2.25 \log _{10} \mathrm{EID}_{50}$ within 5 DPI in oropharyngeal swabs and $1.83 \log _{10} \mathrm{EID}_{5}$ to $2.00 \log _{10} \mathrm{EID}_{50}$ within 7 DPI in cloacal swabs, respectively (Table 6). In the naive contact group of $\mathrm{NH}-10$, The virus could be detected from oropharyngeal swabs at $3 \mathrm{DPI}\left(1.58 \log _{10} \mathrm{EID}_{50}\right)$. According to these, the shedding time and virus titers of SS-10 virus were longest and highest among the two viruses.

In the ducks study, these results indicate that SS-10 and $\mathrm{NH}-10$ viruses could infect ducks and transmit between ducks by naive contact.
Pathogenicity and transmission in geese To evaluate the pathogenicity of the two viruses in geese, we inoculated intranasally with $10^{6}$ EID $_{50}$ of each virus in a volume of $200 \mu \mathrm{l}$ in geese, and then observed them for 14 days after infection.

In the inoculated group, SS-10 caused one of the three inoculated geese to die on 6 DPI, but no geese from the $\mathrm{NH}-10$ groups died during the 14-day observation period. All the surviving geese seroconverted in the SS-10 and $\mathrm{NH}-10$ groups (Table 2). The SS-10 and $\mathrm{NH}-10$ viruses replicated systemically in geese, which could be detected from all the tested organs except brain and heart on 3 DPI, including the heart, liver, spleen, lung, kidney, brain, trachea, small intestine, bursa of fabricius, thymus, pancreas and cecal tonsils. The SS-10 or NH-10 viruses replicated highly in spleen; the mean titers were 5.58 $\log _{10} \mathrm{EID}_{50}$ and $5.75 \log _{10} \mathrm{EID}_{50}$, respectively (Table 7).

SS-10 and NH-10 viruses shedding from the inoculated ducks were detected in oropharyngeal and cloacal swabs at 3, 5, 7, 9 and 11 DPI. In the SS-10 group, the virus titers of the oropharyngeal swabs were from $1.67 \log _{10} \mathrm{EID}_{50}$ to $2.67 \log _{10} \mathrm{EID}_{50}$ within 5 DPI. The virus titers of cloacal swabs were from $1.60 \log _{10} \mathrm{EID}_{50}$ to $1.92 \log _{10} \mathrm{EID}_{50}$ within 7 DPI (Table 8). The NH-10 virus was shed from the oropharynx in inoculated geese within 7 DPI, whose virus titers were from $1.58 \log _{10} \mathrm{EID}_{50}$ to $2.38 \log _{10} \mathrm{EID}_{50}$. It also could be shed from the cloaca within $5 \mathrm{DPI}$; the virus titers were from $1.75 \log _{10} \mathrm{EID}_{50}$ to $2.08 \log _{10} \mathrm{EID}_{50}$ (Table 8).

To understand the horizontal transmission of these two viruses, three geese were inoculated intranasally with $0.2 \mathrm{ml}$ phosphate buffered saline (PBS) as a naive contact group, which was housed with those inoculated with the two viruses described previously.

The SS-10 virus caused one of the three naive contact geese to die, and could be isolated from oropharyngeal and cloacal swabs during the observed period. The mean virus titers of the oropharyngeal swabs were $1.58 \log _{10} \mathrm{EID}_{50}$ within 5 DPI (Table 8). And the virus titers of cloacal swabs could be detected from $2.08 \log _{10} \mathrm{EID}_{50}$ to $3.00 \log _{10} \mathrm{EID}_{50}$ at 3 and 5 DPI (Table 8). In the naive contact group of $\mathrm{NH}-10$, the virus titers of the oropharyngeal swabs were from $1.58 \log _{10} \mathrm{EID}_{50}$ to $3.17 \log _{10} \mathrm{EID}_{50}$ within $7 \mathrm{DPI}$. The virus could be detected from oropharyngeal and cloacal swabs within 7 DPI. The virus titers were from 1.58 $\log _{10} \mathrm{EID}_{50}$ to $3.17 \log _{10} \mathrm{EID}_{50}$ in oropharyngeal swabs and $1.58 \log _{10} \mathrm{EID}_{5}$ to $2.00 \log _{10} \mathrm{EID}_{50}$ in cloacal swabs (Table 8).

Our results indicated that SS-10 virus was highly pathogenic to geese, and could transmit between geese by naive contact. The NH-10 virus could infect geese and transmit between geese by naive contact.

\section{Discussion}

Historically, ND has been a devastating disease in poultry, and in many countries the disease remains one 
Table 4 Virus titers in cloacal and oropharyngeal swabs from chickens

\begin{tabular}{|c|c|c|c|c|c|c|c|c|c|c|c|}
\hline \multicolumn{2}{|c|}{ Strains } & \multicolumn{10}{|c|}{ Days post-inoculation $\left(\log _{10} \mathrm{EID}_{50} / 0.1 \mathrm{~mL}\right) \pm \mathrm{SD}^{\mathrm{a}}$} \\
\hline & & \multicolumn{2}{|c|}{3 Day } & \multicolumn{2}{|c|}{5 Day } & \multicolumn{2}{|c|}{7 Day } & \multicolumn{2}{|c|}{9 Day } & \multicolumn{2}{|c|}{11 Day } \\
\hline & & $\begin{array}{c}\text { Oropharyngeal } \\
\text { swabs }\end{array}$ & Cloacal swabs & $\begin{array}{c}\text { Oropharyngeal } \\
\text { swabs }\end{array}$ & Cloacal swabs & $\begin{array}{c}\text { Oropharyngeal } \\
\text { swabs }\end{array}$ & $\begin{array}{l}\text { Cloacal } \\
\text { swabs }\end{array}$ & $\begin{array}{c}\text { Oropharyngeal } \\
\text { swabs }\end{array}$ & $\begin{array}{l}\text { Cloacal } \\
\text { swabs }\end{array}$ & $\begin{array}{c}\text { Oropharyngeal } \\
\text { swabs }\end{array}$ & $\begin{array}{c}\text { Cloacal } \\
\text { swabs }\end{array}$ \\
\hline \multirow[t]{2}{*}{ SS-10 } & Infected ${ }^{b}$ & $4.30 \pm 0.51(6 / 6)$ & $4.5(6 / 6)$ & $2.67 \pm 0.14(3 / 3)$ & $1.75 \pm 0.43(1 / 3)$ & $-d^{\prime}$ & - & - & - & - & - \\
\hline & Contact $^{c}$ & $2.50 \pm 0.25(3 / 3)$ & $3.17 \pm 0.63(3 / 3)$ & $3.42 \pm 0.58(3 / 3)$ & $2.50 \pm 0.75(3 / 3)$ & $1.75(1 / 1)$ & $1.75(1 / 1)$ & $N D^{e}(0 / 1)$ & ND $(0 / 1)$ & $\mathrm{ND}(0 / 1)$ & $\mathrm{ND}(0 / 1)$ \\
\hline \multirow[t]{2}{*}{ NH-10 } & Infected & $3.58 \pm 0.20(6 / 6)$ & $4.04 \pm 0.56(6 / 6)$ & $4.5(1 / 1)$ & $5.25(1 / 1)$ & - & - & - & - & - & - \\
\hline & Contact & $2.42 \pm 0.14(3 / 3)$ & $2.58 \pm 0.14(3 / 3)$ & $4.25 \pm 0.43(3 / 3)$ & $4.67 \pm 0.88(3 / 3)$ & - & - & - & - & - & - \\
\hline
\end{tabular}

${ }^{\mathrm{a}}$ For statistical purposes, a value of 1.5 was assigned if virus was not detected from the undiluted sample in three embryonated hen's eggs [17].

${ }^{\mathrm{b}}$ Chickens inoculated with virus.

'Naive contact chickens housed with those inoculated.

${ }^{\mathrm{d}}$ All the chickens died at the end of the observation.

${ }^{\mathrm{e}}$ No detected. 
Table 5 Replication in ducks of NDV after inoculated intranasally $^{a}$

\begin{tabular}{crr}
\hline Virus replication on 3 DPI $\left(\log _{10} \mathrm{EID}_{\mathbf{5 0}} / \mathbf{g}\right)^{\mathbf{b}}$ in: & \multicolumn{2}{c}{ Strains } \\
\cline { 2 - 3 } & \multicolumn{1}{c}{ SS-10 } & NH-10 \\
\hline Heart & $\mathrm{ND}$ & $1.58 \pm 0.14$ \\
Liver & $\mathrm{ND}$ & $\mathrm{ND}$ \\
Spleen & $3.58 \pm 0.14$ & $3.58 \pm 0.14$ \\
Lung & $2.58 \pm 0.14$ & 2.50 \\
Kidney & $2.17 \pm 0.95$ & $2.08 \pm 1.01$ \\
Brain & $1.58 \pm 0.14$ & $\mathrm{ND}$ \\
Trachea & $2.00 \pm 0.66$ & $2.00 \pm 0.66$ \\
Small intestine & $2.75 \pm 0.43$ & $3.42 \pm 0.88$ \\
Bursa of fabricius & $3.83 \pm 0.38$ & 3.50 \\
Thymus & $4.08 \pm 1.01$ & $4.17 \pm 0.95$ \\
Pancreas & $2.17 \pm 0.95$ & $1.67 \pm 0.14$ \\
Cecal tonsils & $2.67 \pm 0.14$ & $2.58 \pm 0.14$ \\
\hline
\end{tabular}

${ }^{a}$ Two-week-old ducks were inoculated intranasally (i.n.) with $10^{6} \mathrm{EID}_{50}$ of each virus in a $0.2 \mathrm{ml}$ volume; three ducks in each group were euthanized on $3 \mathrm{DPI}$, and virus titer was determined in samples of heart, liver, spleen, lung, kidney, brain, trachea, Small intestine, bursa of fabricius, Thymus, Pancreas and cecal tonsils in eggs [17].

${ }^{b}$ For statistical analysis, a value of 1.5 was assigned if the virus was not detected from the undiluted sample in three embryonated hen eggs. Virus titers are expressed as means \pm standard deviation in $\log _{10} \mathrm{EID}_{50} / \mathrm{g}$ of tissue. cNo detected.

of the major problems affecting existing and developing poultry industries. Even in countries where ND may be considered to be controlled, an economic burden is still associated with vaccination and maintaining strict biosecurity measures [2]. Around the world, over 241 different bird species have been reported to be susceptible to NDV as a result of natural or experimental infections, and it is likely that many more susceptible species exist but have not yet been identified.

Though waterfowl are considered the natural reservoirs of NDVs and mostly harbor lentogenic strains, surveillance for avirulent Newcastle disease viruses in domestic ducks were regularity isolated from duck farms in the China $[14,18]$. In this study, two strains isolated from China were genotypically and pathotypically characterized during 2010. Pathogenicity results revealed that both isolates (SS-10 and NH-10) were velogenic. The two NDV isolates isolated from ducks were highly pathogenic for chickens and geese, but low pathogenic for ducks. This suggests that NDV from waterfowl were highly pathogenic to terrestrial birds and waterfowl, and might transmit among them. The two NDV exhibited different biological properties with respect to pathogenicity and transmission in chickens, ducks and geese. The SS-10 virus isolated from ducks was highly pathogenic for chickens and geese, but low pathogenic for ducks. Moreover, it could transmit to chickens, ducks and geese by naive contact. However, the $\mathrm{NH}-10$ virus isolated from ducks could infect some chickens, ducks and geese, but only caused chickens to die. Additionally, it could transmit to the naive contact chickens, ducks, and geese. Therefore, our findings showed that the pathogenicity and transmission in birds of the two viruses varied. This suggests that the presence of multiple NDV strains in South China and the highly transmissible nature of the virus can complicate and increase the cost of attempts to prevent the spread of infection to the rest of china and other parts of the world.

Even though most of duck-origin NDV strains are nonpathogenic in ducks, duck-origin NDV strains remain potential threats to the poultry industry. Firstly, the two viruses are able to replicate in most tissues in ducks, especially in the lymphoid tissues (spleen, bursa of fabricius, thymus and cecal tonsils), even though there were no clinical signs or gross lesions, indicating that ducks may carry duck-origin NDV strains without overtsigns of clinical disease and are likely to shed viruses via the oral or cloacal route. Secondly, duck-origin NDV strains passaged in ducks enhanced virulence (date not shown). Finally, the two NDV viruses exhibited highly pathogenic for chickens and geese, and replicated systemically in the inoculated chickens and geese. Therefore, outbreaks by highly pathogenic NDVs can occur by the introduction of benign viruses into waterfowl followed by serial passages under natural conditions, emphasizing the importance of the host environment in the process of NDV selection.

Nowadays, vaccine strains Lasota, B1 and V4 are used widely in China to control the infection of NDV. However, virulent NDV strains are still isolated frequently in the vaccinated birds [14], which demonstrates that NDV remains an on-going threat to commercial flocks. The outbreaks of Newcastle disease in the vaccinated poultry flocks raised concerns on the protective efficiency of commercially available vaccines. Sporadic cases of ND in commercial farms vaccinated with Lasota vaccine were previously reported in China $[11,19,20]$, in Southern California and adjacent states [21], in Indonesia [22], Venezuela [23], Egypt [24], Nigeria and Burkina Faso [25]. It is however possible that NDV strains responsible for ND sporadic outbreaks in vaccinated chickens can escape the immune responses, and thus contribute to the emergence of new genotypes [10]. Thus, the control of NDV by vaccination still faces new challenges in different avian species.

To sum up, it is an urgent to take stricter biosecurity measures in poultry breeding management, in particular to avoid mixing different types of poultry rearing in order to reduce cross-species transmission. Additionally, we also strengthen immunoprophylaxis and regular monitoring of ducks, geese and other waterfowl of the NDV geographic distribution. The present investigation provides important information on the epidemiology, diagnosis and control of NDV in South China and highlights the importance of 
Table 6 Virus titers in cloacal and oropharyngeal swabs from ducks

\begin{tabular}{|c|c|c|c|c|c|c|c|c|c|c|c|}
\hline \multicolumn{2}{|c|}{ Strains } & \multicolumn{10}{|c|}{ Days post-inoculation $\left(\log _{10} \mathrm{EID}_{50} / 0.1 \mathrm{~mL}\right) \pm S D^{\mathrm{a}}$} \\
\hline & & \multicolumn{2}{|c|}{3 Day } & \multicolumn{2}{|c|}{5 Day } & \multicolumn{2}{|c|}{7 Day } & \multicolumn{2}{|l|}{9 Day } & \multicolumn{2}{|c|}{11 Day } \\
\hline & & $\begin{array}{c}\text { Oropharyngeal } \\
\text { swabs }\end{array}$ & Cloacal swabs & $\begin{array}{l}\text { Oropharyngeal } \\
\text { swabs }\end{array}$ & Cloacal swabs & $\begin{array}{c}\text { Oropharyngeal } \\
\text { swabs }\end{array}$ & Cloacal swabs & $\begin{array}{l}\text { Oropharyngeal } \\
\text { swabs }\end{array}$ & $\begin{array}{l}\text { Cloacal } \\
\text { swabs }\end{array}$ & $\begin{array}{c}\text { Oropharyngeal } \\
\text { swabs }\end{array}$ & $\begin{array}{l}\text { Cloacal } \\
\text { swabs }\end{array}$ \\
\hline \multirow[t]{2}{*}{ SS-10 } & Infected $^{\mathbf{b}}$ & $1.96 \pm 0.60(4 / 6)$ & $1.89 \pm 0.76(2 / 6)$ & $N D^{d}(0 / 3)$ & ND (0/3) & $\mathrm{ND}(0 / 3)$ & $\mathrm{ND}(0 / 3)$ & $\mathrm{ND}(0 / 3)$ & $\mathrm{ND}(0 / 3)$ & ND (0/3) & $N D(0 / 3)$ \\
\hline & Contact $^{\mathrm{c}}$ & $1.75 \pm 0.43(1 / / 3)$ & ND (0/3) & $2.25 \pm 1.30(1 / 3)$ & $2.00 \pm 0.43(2 / 3)$ & ND (0/3) & $1.83 \pm 0.57(1 / 3)$ & $\mathrm{ND}(0 / 3)$ & $\mathrm{ND}(0 / 3)$ & ND (0/3) & ND $(0 / 3)$ \\
\hline \multirow[t]{2}{*}{$\mathrm{NH}-10$} & Infected & $2.17 \pm 1.04(2 / 6)$ & $2.17 \pm 1.04(2 / 6)$ & ND (0/3) & $1.58 \pm 0.14(1 / 3)$ & ND (0/3) & $1.58 \pm 0.14(1 / 3)$ & $N D(0 / 3)$ & $\mathrm{ND}(0 / 3)$ & $\mathrm{ND}(0 / 3)$ & $\mathrm{ND}(0 / 3)$ \\
\hline & Contact & $1.58 \pm 0.14(1 / 3)$ & ND (0/3) & ND (0/3) & ND (0/3) & $\mathrm{ND}(0 / 3)$ & $\mathrm{ND}(0 / 3)$ & $N D(0 / 3)$ & $\mathrm{ND}(0 / 3)$ & $\mathrm{ND}(0 / 3)$ & $\mathrm{ND}(0 / 3)$ \\
\hline
\end{tabular}

${ }^{\mathrm{a}}$ For statistical purposes, a value of 1.5 was assigned if virus was not detected from the undiluted sample in three embryonated hen's eggs [17].

${ }^{b}$ Ducks inoculated with virus.

'Naive contact ducks housed with those inoculated.

No detected. 
Table 7 Replication in geese of the NDV viruses after inoculated intranasally ${ }^{a}$

\begin{tabular}{crr}
\hline Virus replication on $\mathbf{3} \mathbf{D P I}\left(\log _{10} \mathrm{EID}_{\mathbf{5 0}} / \mathbf{g}\right)^{\mathbf{b}}$ in: & \multicolumn{2}{c}{ Strains } \\
\cline { 2 - 3 } & $\mathrm{SS}-10$ & $\mathbf{N H}-\mathbf{1 0}$ \\
\hline Heart & $2.08 \pm 1.01$ & $2.17 \pm 0.95$ \\
Liver & $5.58 \pm 1.01$ & $5.75 \pm 0.50$ \\
Spleen & $3.83 \pm 0.38$ & $3.08 \pm 0.58$ \\
Lung & $3.5 \pm 1.75$ & $3.00 \pm 1.39$ \\
Kidney & $\mathrm{ND}$ & $\mathrm{ND}$ \\
Brain & $1.92 \pm 0.72$ & $1.92 \pm 0.72$ \\
Trachea & $4.08 \pm 0.58$ & $3.00 \pm 1.39$ \\
Small intestine & $4.00 \pm 0.66$ & $4.50 \pm 0.75$ \\
Bursa of fabricius & $4.92 \pm 0.52$ & $5.33 \pm 0.52$ \\
Thymus & $2.58 \pm 1.01$ & $1.92 \pm 0.28$ \\
Pancreas & $4.08 \pm 0.58$ & $4.83 \pm 0.38$ \\
Cecal tonsils &
\end{tabular}

${ }^{a}$ Two-week-old geese were inoculated intranasally (i.n.) with $10^{6} \mathrm{EID}_{50}$ of each virus in a $0.2 \mathrm{ml}$ volume; three ducks in each group were euthanized on $3 \mathrm{DPI}$, and virus titer was determined in samples of heart, liver, spleen, lung, kidney, brain, trachea, Small intestine, bursa of fabricius, Thymus, Pancreas and cecal tonsils in eggs [17].

${ }^{\mathrm{b}}$ For statistical analysis, a value of 1.5 was assigned if the virus was not detected from the undiluted sample in three embryonated hen eggs. Virus titers are expressed as means \pm standard deviation in $\log _{10} \mathrm{EID}_{50} / \mathrm{g}$ of tissue. cNo detected.

supporting surveillance in developing countries for transboundary animal diseases.

\section{Materials and methods Viruses}

In 2010, two Newcastle disease viruses Duck/CH/GD/ SS/10 (SS-10) and Duck/CH/GD/NH/10 (NH-10) were isolated from cloacal swabs of apparently healthy birds in live bird markets during 2010. All viruses were propagated in 10-day-old embryonated specific-pathogen-free (SPF) chicken eggs. All experiments were carried out in animal biosafety level 3 (ABSL-3) facilities. All animal procedures performed in this study were reviewed, approved, and supervised by the Guangdong Administration Committee of Laboratory Animals under the leadership of the Guangdong Association for Science and Technology, permit number SCXK(Guangdong)2008-0019.

Assessment of the biological characteristics of two isolates The pathogenic potential for the two isolated viruses were evaluated using standard assay methods to determine the MDT in 10-day-old chick embryos and the ICPI in 1-day-old chicks [2]. The $50 \%$ embryo infectious doses $\left(\right.$ EID $\left._{50}\right)$ of two isolates were also determined with 10-day-old chick embryos and calculated by the method of Reed and Muench [26].

\section{Complete genome amplification of these two virus strains by RT-PCR}

Viral RNA was isolated from these two NDV-infected allantoic fluids of 10-day-old SPF chicken embryos, using an RNeasy mini kit (Qiagen, Valencia, CA) according to manufacturer's recommendations and transcribed into cDNA with SuperScript III reverse transcriptase (Invitrogen). Amplification reactions were performed with the one-step RT-PCR kit (Qiagen, Valencia, CA). PCR was performed using fragment-specific primers. A set of 12 pairs of specific primers (see Table 9) were designed to amplify the complete genome of SS-10 and $\mathrm{NH}-10$ which were based on the available NDV nucleotide sequences (GM, ZJ1, JS/ 1/02/Du, F48E9, JS/1/97/Ch, ZJ/1/86/Ch, and Duck/1/05, with GenBank accession numbers DQ486859, AF431744, FJ436306, AY508514, FJ436305, FJ436303 and EU649675, respectively). The PCR products of the expected length were subjected to electrophoresis in 1\% agarose gels purified by using the QuickClean DNA gel extraction kit (Qiagen, Valencia, CA).

\section{Nucleotide sequencing and phylogenetic analysis}

The purified PCR products were sequenced using an automatic ABI Prism 3730 genetic analyzer (Applied Biosystems) according to the manufacturer's instructions. Nucleotide sequence editing, analysis, the prediction of amino acid sequences and alignments were performed using the MegAlign program in the Lasergene package (Laser-Gene, version 5.07; DNAStar, Inc., Madison, WI). The sequences of the two isolates were compared with 62 previously reported NDV sequences representative of different genotypes available in GenBank (Additional file 1: Table S1). Phylogenetic trees were constructed by the neighbor-joining method of MEGA 4 [16] by a comparison of the nucleotide sequences of the entire ORF of the $\mathrm{F}$ gene from 1 to 1,662 nucleotides (nt) and the complete genome from 1 to 15192 nt [27]. The reliability of the tree was assessed by bootstrap analysis with 1000 replicates. Horizontal distances are proportional to genetic distance. Putative recombination events in the two fullgenomes of SS-10 and $\mathrm{NH}-10$ isolates were examined using the SimPlot program (version 3.5) [28].

\section{Animal experiment}

\section{Pathogenicity and transmission in chickens}

Six-week-old SPF White Leghorn chickens were purchased from Guangdong Dahuanong and housed in the isolator cages and randomly divided into 2 groups. Six chickens of the SS-10 group were inoculated intranasally with $10^{6} \mathrm{EID}_{50}$ of SS-10 viruses in a $0.2 \mathrm{ml}$ volume. Six chickens of the $\mathrm{NH}-10$ group were inoculated intranasally with $10^{6} \mathrm{EID}_{50}$ of $\mathrm{NH}-10$ viruses in a $0.2 \mathrm{ml}$ volume Three chickens were inoculated intranasally with $0.2 \mathrm{ml}$ phosphate buffered saline (PBS) as naïve contact group 
Table 8 Virus titers in cloacal and oropharyngeal swabs from geese

\begin{tabular}{|c|c|c|c|c|c|c|c|c|c|c|c|}
\hline \multicolumn{2}{|c|}{ Strains } & \multicolumn{10}{|c|}{ Days post-inoculation $\left(\log _{10} \mathrm{EID}_{50} / 0.1 \mathrm{~mL}\right) \pm \mathrm{SD}^{\mathrm{a}}$} \\
\hline & & \multicolumn{2}{|c|}{3 Day } & \multicolumn{2}{|c|}{5 Day } & \multicolumn{2}{|c|}{7 Day } & \multicolumn{2}{|l|}{9 Day } & \multicolumn{2}{|c|}{11 Day } \\
\hline & & $\begin{array}{c}\text { Oropharyngeal } \\
\text { swabs }\end{array}$ & Cloacal swabs & $\begin{array}{c}\text { Oropharyngeal } \\
\text { swabs }\end{array}$ & Cloacal swabs & $\begin{array}{c}\text { Oropharyngeal } \\
\text { swabs }\end{array}$ & Cloacal swabs & $\begin{array}{l}\text { Oropharyngeal } \\
\text { swabs }\end{array}$ & $\begin{array}{l}\text { Cloacal } \\
\text { swabs }\end{array}$ & $\begin{array}{c}\text { Oropharyngeal } \\
\text { swabs }\end{array}$ & $\begin{array}{l}\text { Cloacal } \\
\text { swabs }\end{array}$ \\
\hline \multirow[t]{2}{*}{ SS-10 } & Infected $^{\mathbf{b}}$ & $2.67 \pm 0.79(5 / 6)$ & $1.60 \pm 0.14(3 / 6)$ & $1.67 \pm 0.14(2 / 3)$ & $1.92 \pm 0.72(1 / 3)$ & $N D^{d}(0 / 3)$ & $1.88 \pm 0.53(2 / 3)$ & $\mathrm{ND}(0 / 3)$ & $\mathrm{ND}(0 / 3)$ & $\mathrm{ND}(0 / 3)$ & $\mathrm{ND}(0 / 3)$ \\
\hline & Contact $^{c}$ & $1.58 \pm 0.14(1 / 3)$ & $2.08 \pm 1.01(2 / 3)$ & $1.58 \pm 0.14(1 / 3)$ & $3.00 \pm 1.30(2 / 3)$ & $\mathrm{ND}(0 / 3)$ & $N D(0 / 3)$ & $N D(0 / 3)$ & $\mathrm{ND}(0 / 3)$ & $\mathrm{ND}(0 / 3)$ & $\mathrm{ND}(0 / 3)$ \\
\hline \multirow[t]{2}{*}{$\mathrm{NH}-10$} & Infected & $2.38 \pm 0.38(6 / 6)$ & $2.08 \pm 0.90(2 / 6)$ & $2.17 \pm 1,15(1 / 3)$ & $1.75 \pm 0.43(1 / 3)$ & $1.58 \pm 0.14(1 / 3)$ & $N D(0 / 3)$ & $N D(0 / 3)$ & $\mathrm{ND}(0 / 3)$ & $\mathrm{ND}(0 / 3)$ & $\mathrm{ND}(0 / 3)$ \\
\hline & Contact & $3.17 \pm 0.95(3 / 3)$ & $2.00 \pm 0.66(2 / 3)$ & $1.58 \pm 0.14(1 / 3)$ & $1.75 \pm 0.43(1 / 3)$ & $1.58 \pm 0.14(1 / 3)$ & $1.58 \pm 0.14(1 / 3)$ & $\mathrm{ND}(0 / 3)$ & $\mathrm{ND}(0 / 3)$ & $\mathrm{ND}(0 / 3)$ & $\mathrm{ND}(0 / 3)$ \\
\hline
\end{tabular}

${ }^{a}$ For statistical purposes, a value of 1.5 was assigned if virus was not detected from the undiluted sample in three embryonated hen's eggs [17].

${ }^{\mathrm{b}}$ Geese inoculated with virus.

'Naive contact geese housed with those inoculated.

dNo detected. 
Table 9 Primers used in the study

\begin{tabular}{|c|c|c|c|c|}
\hline Primers & Sequences $\left(5^{\prime}-3^{\prime}\right)$ & Position & Expected extent (bp) & Expected size (bp) \\
\hline$\overline{1 F^{a}}$ & ACCAAACAGAGAATCCGTGAG & $1-21$ & $1-1270$ & 1270 \\
\hline $1 R^{b}$ & CTITAGCTCGGCAGCCATATCCTC & $1258-1270$ & & \\
\hline $2 \mathrm{~F}$ & TGAGCACATCATTCTGGAGACTTG & 1185-1207 & $1185-2280$ & 1096 \\
\hline $2 \mathrm{R}$ & TGGACGATTTATTGCTAAGCTTG & $2259-2280$ & & \\
\hline $3 F$ & CTAAGCACAGCATGGGAGAAG & $2025-2046$ & $2025-3432$ & 1408 \\
\hline $3 R$ & AAGTCAAGACGCTGGATCCT & 3413-3432 & & \\
\hline $4 \mathrm{~F}$ & CACAGGAGATGGGAAGAAGC & $3376-3395$ & $3376-5330$ & 1955 \\
\hline $4 \mathrm{R}$ & ATGAGCTGAGTTGATTGTTCC & $5310-5330$ & & \\
\hline $5 F$ & CAGTTGGGAAGATGCAGCAG & $5076-5095$ & $5076-6873$ & 1798 \\
\hline $5 R$ & AGAGGGATAGAATGATGTGAC & $6853-6873$ & & \\
\hline $6 \mathrm{~F}$ & CCTGTTCATGACCCAGACTAC & $6787-6807$ & $6787-8520$ & 1734 \\
\hline $6 \mathrm{R}$ & TCGAAGTCACATTCATCAGG & $8501-8520$ & & \\
\hline $7 F$ & GATCAGATGAGAGCCACTACAA & $6471-6492$ & $6471-8448$ & 1978 \\
\hline $7 R$ & GATAGATGTGACTCTGGTAGGAT & $8426-8448$ & & \\
\hline $8 \mathrm{~F}$ & AGAGGGAACACGGGTAGGA & 8376-8394 & $8367-10054$ & 1688 \\
\hline $8 \mathrm{R}$ & CTTAGCAAAAATCCGCCCA & 10036-10054 & & \\
\hline $9 F$ & ATCGTACTCACTCAAAGAGA & 10000-10019 & $10000-11747$ & 1748 \\
\hline $9 \mathrm{R}$ & GGGCATAATCTGCTAGCGTC & 11728-11747 & & \\
\hline $10 \mathrm{~F}$ & TGACGCTAGCAGATTATG & $11727-11744$ & $11727-13422$ & 1696 \\
\hline $10 \mathrm{R}$ & TCCTGAGGGAACAACAAT & $13405-13422$ & & \\
\hline $11 \mathrm{~F}$ & TCTTTCCAATGACAACAACC & $12604-12623$ & $12604-14589$ & 1986 \\
\hline $11 \mathrm{R}$ & GACCGGATAACTGTGTCAAT & $14570-14589$ & & \\
\hline $12 \mathrm{~F}$ & AAGATTCGTCCAGGGTCC & 14033-14050 & 14 033-15 192 & 1160 \\
\hline $12 \mathrm{R}$ & ACCAAACAGAGATTTGGTGAA & 15172-15192 & & \\
\hline
\end{tabular}

${ }^{\mathrm{a}} \mathrm{F}$ stands for forward primer.

${ }^{\mathrm{b}} \mathrm{R}$ stands for reverse primer.

housed with those inoculated with the SS-10 or NH-10 viruses, respectively. All chickens were observed for clinical symptoms for 14 days. On 3-day post-inoculated (DPI), three inoculated chickens in each group were euthanized to test the virus replication in organs, including heart, liver, spleen, lung, kidney, brain, trachea, small intestine, bursa of fabricius, thymus, pancreas and cecal tonsils. Similar actions were performed on chickens that had died. Oropharyngeal and cloacal swabs were taken from chickens at 3, 5, 7, 9 and 11 DPI, and suspended in $1 \mathrm{ml}$ PBS. All of the tissues and swabs were collected and titrated for virus infectivity in SPF chick embryos. Seroconversion of the surviving birds on 14 DPI was confirmed by hemagglutinin inhibition (HI) test.

\section{Pathogenicity and transmission in ducks}

Eighteen two-week-old healthy Peking ducks were purchased from a duck farm in Guangzhou and housed in the isolators and randomly divided into 2 groups. Peking ducks were confirmed serologically negative for Newcastle disease by hemagglutination inhibition (HI) assays. Six of nine ducks were inoculated intranasally with $10^{6} \mathrm{EID}_{50}$ of each virus in a $0.2 \mathrm{ml}$ volume. The other three ducks were inoculated intranasally with $0.2 \mathrm{ml} \mathrm{PBS}$ as a naive contact group housed with those inoculated with the SS-10 or $\mathrm{NH}-10$ viruses, respectively. Three inoculated ducks in each group were euthanized to test the virus replication in organs on 3 DPI, including heart, liver, spleen, lung, kidney, brain, trachea, small intestine, bursa of fabricius, thymus, pancreas and cecal tonsils, and the six remaining ducks were observed for clinical symptoms (inappetence, lethargy, greenish or white watery diarrhoea, dyspnoea, tremors, morbidity and mortality) for 14 days. Swabs from the oropharynx and cloaca were collected for detection of viruses shedding at 3, 5, 7, 9 and 11 DPI. All of the tissues and swabs were collected and titrated for virus infectivity in SPF chick embryos. Seroconversion of the surviving birds on 14 DPI was confirmed by HI test.

\section{Pathogenicity and transmission in geese}

Two groups of two-week-old healthy domestic geese (Qingyuan geese) were purchased from a goose farm in 
Guangzhou and housed in isolators. Geese were confirmed serologically negative for Newcastle disease by hemagglutination inhibition (HI) assays. Six geese of each group were inoculated intranasally with $10^{6} \mathrm{EID}_{50}$ of each virus in a $0.2 \mathrm{ml}$ volume. Three geese were inoculated with $0.2 \mathrm{ml} \mathrm{PBS}$ as a naive contact group housed with those inoculated with the SS-10 or NH-10 viruses, respectively. On 3 DPI, three inoculated geese in each group were euthanized to test the virus replication in organs, including heart, liver, spleen, lung, kidney, brain, trachea, small intestine, bursa of fabricius, thymus, pancreas and cecal tonsils. Oropharyngeal and cloacal swab specimens were collected at 3, 5, 7, 9 and 11 DPI. All of the tissues and swabs were collected and titrated for virus infectivity in SPF chick embryos. Seroconversion of the surviving birds on 14 DPI was confirmed by HI test.

\section{Additional file}

Additional file 1: Table S1. NDV isolates and their accession numbers used in phylogenetic analysis.

\section{Competing interests}

The authors declare that they have no competing interests.

\section{Authors' contributions}

Conceived and designed the experiments:YK XL RY. Performed the experiments: YK RY MS. Analyzed the data: YK XL RY MS ZW. Contributed reagents/materials/analysis tools: ZW YL TR. Wrote the paper: YK XL RY. All authors read and approved the final manuscript.

\section{Acknowledgment}

This study was mainly funded by grants from the National Natural Science Foundation of China (No.31072139, No. 31372412), the Chinese Special Fund for Agro-scientific Research in the Public Interest (No.201303033), the Science and Technology Projects of Guangdong Province (No.2012A020800006), and Doctoral Fund of Ministry of Education of China (No. 20124404110016). The funders had no role in study design, data collection and analysis, decision to publish, or preparation of the manuscript.

\section{Author details}

${ }^{1}$ National and Regional Joint Engineering Laboratory for Medicament of Zoonosis Prevention and Control, Guangzhou, China. ${ }^{2}$ Key Laboratory of Animal Vaccine Development, Ministry of Agriculture, Guangzhou, China. ${ }^{3}$ Key Laboratory of Zoonosis Prevention and Control of Guangdong, Guangzhou, China. ${ }^{4}$ College of Veterinary Medicine, South China Agricultural University, 483 Wushan Road, Tianhe District, Guangzhou 510642, P.R. China.

Received: 28 February 2014 Accepted: 8 August 2014 Published: 12 August 2014

\section{References}

1. Swayne DE, Glisson JR, Jackwood MW, Pearson JE, Reed WM: A Laboratory Manual for the Isolation and Identification of Avian Pathogens. PA: American Association of Avian Pathologists Philadelphia; 1998.

2. Alexander DJ: Newcastle disease and other avian paramyxoviruses. Rev Sci Tech 2000, 19:443-462.

3. Truszczynsky M, Pearson J, Edwards S: Manual of Standards for Diagnostic Tests and Vaccines. Paris: Office International des Epizooties; 1992.

4. Kattenbelt JA, Stevens MP, Gould AR: Sequence variation in the Newcastle disease virus genome. Virus Res 2006, 116:168-184.

5. Panda A, Huang Z, Elankumaran S, Rockemann DD, Samal SK: Role of fusion protein cleavage site in the virulence of Newcastle disease virus. Microb Pathog 2004, 36:1-10.
6. Peeters BP, de Leeuw OS, Koch G, Gielkens AL: Rescue of Newcastle disease virus from cloned CDNA: evidence that cleavability of the fusion protein is a major determinant for virulence. J Virol 1999, 73:5001-5009

7. Collins M, Bashiruddin J, Alexander D: Deduced amino acid sequences at the fusion protein cleavage site of Newcastle disease viruses showing variation in antigenicity and pathogenicity. Arch Virol 1993, 128:363-370.

8. Toyoda T, Sakaguchi T, Imai K, Inocencio NM, Gotoh B, Hamaguchi M, Nagai $Y$ : Structural comparison of the cleavage-activation site of the fusion glycoprotein between virulent and avirulent strains of Newcastle disease virus. Virology 1987, 158:242-247.

9. Glickman RL, Syddall RJ, Iorio RM, Sheehan JP, Bratt MA: Quantitative basic residue requirements in the cleavage-activation site of the fusion glycoprotein as a determinant of virulence for Newcastle disease virus. $J$ Virol 1988, 62:354-356.

10. Liu XF, Wan HQ, Ni XX, Wu YT, Liu WB: Pathotypical and genotypical characterization of strains of Newcastle disease virus isolated from outbreaks in chicken and goose flocks in some regions of China during 1985-2001. Arch Virol 2003, 148:1387-1403.

11. Yu L, Wang Z, Jiang Y, Chang L, Kwang J: Characterization of newly emerging Newcastle disease virus isolates from the People's Republic of China and Taiwan. J Clin Microbiol 2001, 39:3512-3519.

12. Jinding C, Ming L, Tao R, Chaoan X: A goose-sourced paramyxovirus isolated from southern China. Avian Dis 2005, 49:170-173.

13. Qin ZM, Tan LT, Xu HY, Ma BC, Wang YL, Yuan XY, Liu WJ: Pathotypical characterization and molecular epidemiology of Newcastle disease virus isolates from different hosts in China from 1996 to 2005. J Clin Microbiol 2008, 46:601-611.

14. Liu X, Wang X, Wu S, Hu S, Peng Y, Xue F: Surveillance for avirulent Newcastle disease viruses in domestic ducks (Anas platyrhynchos and Cairina moschata) at live bird markets in Eastern China and characterization of the viruses isolated. Avian Pathol 2009, 38:377-391.

15. Diel DG, da Silva LH, Liu H, Wang Z, Miller PJ, Afonso CL: Genetic diversity of avian paramyxovirus type 1: proposal for a unified nomenclature and classification system of Newcastle disease virus genotypes. Infect Genet Evol 2012, 12:1770-1779.

16. Tamura K, Dudley J, Nei M, Kumar S: MEGA4: molecular evolutionary genetics analysis (MEGA) software version 4.0. Mol Biol Evol 2007, 24:1596-1599.

17. Yuan R, Cui J, Zhang S, Cao L, Liu X, Kang Y, Song Y, Gong L, Jiao P, Liao M: Pathogenicity and transmission of $\mathrm{H} 5 \mathrm{~N} 1$ avian influenza viruses in different birds. Vet Microbiol 2014, 168:50-59.

18. Zhang S, Wang X, Zhao C, Liu D, Hu Y, Zhao J, Zhang G: Phylogenetic and pathotypical analysis of two virulent Newcastle disease viruses isolated from domestic ducks in China. PLoS One 2011, 6:e25000.

19. Cho SH, Kim SJ, Kwon HJ: Genomic sequence of an antigenic variant Newcastle disease virus isolated in Korea. Virus Genes 2007, 35:293-302.

20. Cai S, Li J, Wong MT, Jiao P, Fan H, Liu D, Liao M, Jian J, Shi M, Lam TT, Ren T, Leung FC: Genetic characterization and evolutionary analysis of 4 Newcastle disease virus isolate full genomes from waterbirds in South China during 2003-2007. Vet Microbiol 2011, 152:46-54.

21. Kapczynski DR, King DJ: Protection of chickens against overt clinical disease and determination of viral shedding following vaccination with commercially available Newcastle disease virus vaccines upon challenge with highly virulent virus from the California 2002 exotic Newcastle disease outbreak. Vaccine 2005, 23:3424-3433.

22. Xiao S, Paldurai A, Nayak B, Samuel A, Bharoto EE, Prajitno TY, Collins PL, Samal SK: Complete genome sequences of Newcastle disease virus strains circulating in chicken populations of Indonesia. J Virol 2012, 86:5969-5970.

23. Perozo F, Marcano R, Afonso CL: Biological and phylogenetic characterization of a genotype VII Newcastle disease virus from Venezuela: efficacy of field vaccination. J Clin Microbiol 2012, 50:1204-1208.

24. Mohamed MH, Kumar S, Paldurai A, Samal SK: Sequence analysis of fusion protein gene of Newcastle disease virus isolated from outbreaks in Egypt during 2006. Virol J 2011, 8:237.

25. Snoeck CJ, Ducatez MF, Owoade AA, Faleke OO, Alkali BR, Tahita MC, Tarnagda Z, Ouedraogo JB, Maikano I, Mbah PO, Kremer JR, Muller CP: Newcastle disease virus in West Africa: new virulent strains identified in non-commercial farms. Arch Virol 2009, 154:47-54. 
26. Reed $\mathrm{L}$, Muench $\mathrm{H}$ : A simple method of estimating fifty per cent endpoints. Am J Epidemiol 1938, 27:493-497.

27. Seal BS, King DJ, Bennett JD: Characterization of Newcastle disease virus isolates by reverse transcription PCR coupled to direct nucleotide sequencing and development of sequence database for pathotype prediction and molecular epidemiological analysis. J Clin Microbiol 1995, 33:2624-2630

28. Lole KS, Bollinger RC, Paranjape RS, Gadkari D, Kulkarni SS, Novak NG, Ingersoll R, Sheppard HW, Ray SC: Full-length human immunodeficiency virus type 1 genomes from subtype C-infected seroconverters in India, with evidence of intersubtype recombination. J Virol 1999, 73:152-160.

doi:10.1186/1743-422X-11-147

Cite this article as: Kang et al:: Phylogenetic relationships and pathogenicity variation of two Newcastle disease viruses isolated from domestic ducks in Southern China. Virology Journal 2014 11:147.

\section{Submit your next manuscript to BioMed Central and take full advantage of:}

- Convenient online submission

- Thorough peer review

- No space constraints or color figure charges

- Immediate publication on acceptance

- Inclusion in PubMed, CAS, Scopus and Google Scholar

- Research which is freely available for redistribution 